\title{
Subgrup Non Trivial Dari Grup Dihedral
}

\author{
Abdul Gazir S. , I Gede Adhitya Wisnu Wardhana, ${ }^{b, *}$ \\ ${ }^{a}$ Universitas Mataram,Alamat, Kota dan KodePos, Indonesia. Email: abdgazirsyazir@gmail.com \\ bUniversitas Mataram, Alamat, Kota dan KodePos, Indonesia. Email: adhitya.wardhana@unram.ac.id
}

Keywords: Dihedral groups, Dihedral subgroup, Rotation, Reflection.

\begin{abstract}
The dihedral group is a symmetry group of a regular polygon consisting of a rotational element and a reflection element, the group is denoted by $D_{2 n}$. Dihedral groups are studied by chemists or mineralogists to classify molecular and crystalline structures. This paper will discuss subgroups of a dihedral group. One of the results is, if $n$ is prime then the subgroup can be divided into two categories, namely rotational subgroups and reflection subgroups. Another result when $n$ is composites, the subgroup can be divided into three categories, namely rotational subgroups and reflection subgroups and combination of both reflection and rotational subgroups.
\end{abstract}

\section{Keywords: Dihedral groups, Dihedral subgroup, Rotation, Reflection.}

\section{A B S T R A K}

Grup dihedral adalah grup simetri dari sebuah polygon reguler yang terdiri dari unsur rotasi dan unsur refleksi, Grup dihedral dinotasikan dengan $D_{2 n}$. Grup dihedral dipelajari oleh kimiawan atau ahli mineral untuk mengklasifikasikan struktur molekul dan kristal. Pada paper ini akan dibahas subgroup-subgrup dari suatu grup dihedral. Salah satunya hasilnya adalah, jika $n$ prima maka subgroup dapat dibagi kedalam 2 kategori, yaitu subgrup yang mengandung rotasi dan subgrup yang mengandung refleksi. Jika $n$ komposit maka subgroup dapat dibagi menjadi 3 kategori yaitu subgrup yang mengandung rotasi, subgrup yang mengandung refleksi dan subgrup yang mengandung keduanya.

Keywords: Grup Dihedral, Subgrup Dihedral, Rotasi, Refleksi. 


\section{Pendahuluan}

Grup dihedral adalah topik yang menarik karena banyak muncul di alam maupun di karya seni. Untuk karya seni, grup dihedral banyak dijadikan dasar dalam dekorasi lantai, dinding atau pekerjaan seni lainnya. Di alam grup dihedral dipelajari oleh ahli mineral dan ahli kimia untuk mempelajari struktur molekul atau struktur kristal.

Grup dihedral itu sendiri adalah grup simetri dari polygon regular yang terdiri dari unsur rotasi dan unsur refleksi. Grup dihedral disimbolkan dengan $D_{2 n}$, dimana $n$ menunjukkan bentuk dari polygon. Secara matematis grup dihedral didefinisikan sebgai berikut:

\section{Definisi 1.1}

Misalkan $G$ adalah grup. Grup $G$ dikatakan grup dihedral dengan order $2 n, n \geq 3$, adalah grup yang dibangun oleh dua elemen $a, b$ dengan

$G=D_{2 n}=\left\langle a, b \mid a^{n}=e, b^{2}=e, b a b^{-1}=a^{-1}\right\rangle$

Unsur $b$ adalah elemen yang berorde 2 , dan dinamakan unsur refleksi, dan unsur $a$ yang berorde lebih dari $n \geq 3$ dikatakan unsur rotasi. Mudah dilihat bahwa order dari grup dihedral $D_{2 n}$ adalah $2 n$. Sebagai contoh, untuk $n=3$, diperoleh grup dihedral $D_{6}=$ $\left\{e, a, a^{2}, b, a b, a^{2} b\right\}$.

Unsur refleksi $b$ karena berorde 2 maka akan memiliki invers dirinya sendiri. Unsur $b$ tidak satu-satunya unsur refleksi, atau unsur yang berorde 2 pada grup dihedral. Unsur refleksi lain pada grup dihedral mempunyai bentuk sebagai pada Teorema berikut.

\section{Teorema 1.1}

Misalkan $D_{2 n}$ grup dihedral dan $x \in D_{2 n}$ adalah unsur refleksi, maka $x=a^{k} b$ untuk $\in\{1, \ldots, n\}$

Bukti
Untuk menunjukkan $x$ unsur refleksi, akan ditunjukkan $x^{2}=e$. Karena diketahui $b^{-1}=b$ maka $a^{-1}=b a b$. Akibatnya

$$
\begin{gathered}
x^{2}=\left(a^{k} b\right)\left(a^{k} b\right) \\
x^{2}=\left(a^{k-1} e a b\right)\left(a^{k-1} e a b\right) \\
x^{2}=\left(a^{k-1} b^{2} a b\right)\left(a^{k-1} b^{2} a b\right) \\
x^{2}=\left(a^{k-1} b\right)\left(a^{k-1} b\right) \\
x^{2}=\left(a^{k-2} b^{2} a b\right)\left(a^{k-2} b^{2} a b\right) \\
x^{2}=\left(a^{k-2} b\right)\left(a^{k-2} b\right)
\end{gathered}
$$

Proses dapat terus diulangi sehingga

$$
x^{2}=a b a b=a a^{-1}=e
$$

Akibatnya $x$ adalah unsur refleksi.

Dari Teorema 1.1, maka grup dihedral $D_{2 n}$ dapat ditulis ulang sebagai berikut:

$D_{2 n}=\left\{e, a, a^{2} \ldots, a^{n-1}, b, a b, a^{2} b, \ldots, a^{n-1} b\right\}$.

Salah satu sifat menarik dari unsur grup dihedral diberikan oleh Teorema berikut.

\section{Teorema 1.2}

Misalkan $D_{2 n}$ grup dihedral, jika $u \leq n$ maka $a^{r} b a^{n-u}=a^{r} a^{u} b$.

Bukti:

Misalkan $u \leq n$, maka diperoleh

$$
\begin{aligned}
a^{r} b a^{n-u}=a^{r} b a^{-u} & =a^{r} b\left(a^{-1}\right) a^{-u+1} \\
& =a^{r} b(b a b) a^{-u+1} \\
& =a^{r} a b a^{-u+1}
\end{aligned}
$$

Proses dapat diteruskan hingga diperoleh

$$
a^{r} b a^{n-u}=a^{r} a^{u} b .
$$

Grup dihedral untuk selanjutnya akan disimbolkan dengan $D_{2 n}$ pada artikel ini.

\section{Subgrup Dihedral}

Pada bagian ini akan diidentifikasi semua subgrup Dihedral. Untuk mengetahui subgrup dari grup secara umum biasanya digunakan tabel Cayley. Tabel Cayley adalah salah satu cara untuk mendefinisikan operasi biner pada himpunan, khususnya himpunan berhingga. Contohnya grup dihedral $D_{6}=$ $\left\{e, a, a^{2}, b, a b, a^{2} b\right\} \quad$ mempunya subgrup 
nontrivial diantaranya: $S_{1}=\left\{e, a, a^{2}\right\}, \quad S_{2}=$ $\{e, b\}, S_{3}=\{e, a b\}, S_{4}=\left\{e, a^{2} b\right\}$.

Sehingga table Cayley bisa digambar sebagai berikut:

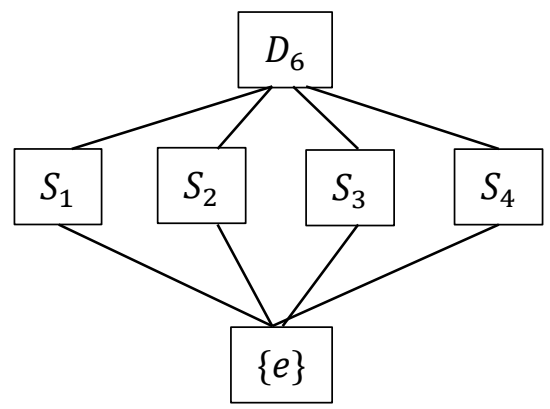

Tabel Cayley akan memberikan hasil berbeda untuk setiap grup $D_{2 n}$. Secara umum, subgroup dari $D_{2 n}$ akan tergantung karakteristik dari $n$. Salah satu karakteristik dari grup dihedral adalah himpunan semua unsur rotasinya membentuk subgrup.

\section{Teorema 2.1}

Diberikan $D_{2 n}$ grup dihedral dengan $n \geq 3$. Jika $R=\left\{e, a, a^{2}, a^{3}, \ldots, a^{n-1}\right\} \subseteq D_{2 n} \quad$ maka $\quad R$ adalah subgrup nontrivial dari $D_{2 n}$.

Bukti

Jelas bahwa $S$ bukan himpunan kosong karena $e=a^{n} \in R$. Selanjutnya ambil sebarang $x, y \in$ $S$, maka $x=a^{r}$ dan $y=a^{s}$, untuk suatu $r, s \in$ $N$. Tanpa mengurangi perumuman, asumsikan $r>s . \quad$ Akibatnya $\quad x y^{-1}=a^{r}\left(a^{s}\right)^{-1}=$ $a^{r} a^{n-s}=a^{n+r-s}=a^{r-s} \in R . \quad$ Dengan demikian terbukti $R$ subgrup dari $D_{2 n}$, dimana atau $R=\langle a\rangle$.

Karakteristik lainnya dari subgroup $D_{2 n}$ adalah, setiap satu unsur refleksi dan unsur identitas membentuk subgroup.

\section{Teorema 2.2}

Diberikan $D_{2 n}$ grup dihedral dengan $n \geq 3$. Jika $S_{i}=\left\{e, a^{i} b\right\} \subseteq D_{2 n}$ dimana $i=0,1,2, \ldots, n-1$ maka $S$ adalah subgrup nontrivial dari $D_{2 n}$.

Bukti

Jelas bahwa $S_{i}$ bukan himpunan kosong karena $e \in S_{i}$. Selanjutnya tinggal ditunjukkan bahwa $a^{i} b$ memiliki invers di $S_{i}$. Berdasarkan Teorema
1.1, maka invers dari $a^{i} b$ adalah dirinya sendiri. Akibatnya $S_{i}$ membentuk subgrup dari $D_{2 n}$.

Subgrup yang diberikan oleh Teorema 2.1 dinamakan subgrup rotasi. Sementara subgrup yang diberikan oleh Teorema 2.2 dinamakan subgrup Refkleksi ke-i. Secara umum, setiap grup dihedral memiliki subgrup rotasi dan subgrup refleksi. Khususnya jika $n$ berupa bilangan prima tidak ada subgrup nontrivial selain $R$ dan $S_{i}$. Apabila $n$ bilangan komposit, grup dihedral mempunyai subgrup yang lebih bervariasi, salah satunya adalah subgrup yang terdiri dari sebagian unsur rotasinya.

\section{Teorema 2.3}

Diberikan $D_{2 n}$ grup dihedral dengan $n \geq 3$ dan $n=p_{1} p_{2} p_{3} \ldots p_{k}$, dengan $p_{i}$ adalah bilangan prima yang berbeda. Maka $R_{i}=$ $\left\{e, a^{p_{i}}, a^{2 p_{i}}, a^{3 p_{i}}, \ldots, a^{n-p_{i}}\right\} \subseteq D_{2 n} \quad$ adalah subgrup nontrivial dari $D_{2 n}$.

Bukti

Jelas bahwa $R_{i}$ bukan himpunan kosong karena $e=a^{n} \in R_{i}$. Selanjutnya ambil sebarang $x, y \in$ $R_{i}$, maka $x=a^{r}$ dan $y=a^{s}$, untuk suatu $r, s \in$ $\left.<p_{i}\right\rangle$. Tanpa mengurangi perumuman, asumsikan $\quad r>s$. Akibatnya $x y^{-1}=$ $a^{r}\left(a^{s}\right)^{-1}=a^{r} a^{n-s}=a^{n+r-s}=a^{r-s} \in R_{i}$.

Dengan demikian terbukti $R_{i}$ subgrup nontrivial dari $D_{2 n}$ yang dibangun oleh $a^{p_{i}}$ atau $R_{i}=<$ $a^{p_{i}}>$.

Selain subgrup $R_{i}$, apabila $n$ komposit kita akan memiliki subgrup yang terdiri dari kombinasi unsur rotasi dan unsur refleksi.

\section{Teorema 2.4}

Diberikan $D_{2 n}$ grup dihedral dengan $n \geq 3$ dan $=p_{1} p_{2} p_{3} \ldots p_{k}$, dengan $p_{i}$ adalah bilangan prima yang berbeda. Maka untuk $i \in\{1,2, \ldots, k\}$ dan $j \in\left\{0,1,2, \ldots, p_{i}-1\right\}, \quad G_{i j}=$ $\left\{e, a^{p_{i}}, a^{2 p_{i}}, \ldots, a^{n-p_{i}}, a^{j} b, a^{j+p_{i}} b, \ldots, a^{j+n-p_{i}}\right\} \subseteq$ $D_{2 n}$ adalah subgrup nontrivial dari $D_{2 n}$.

Bukti

Jelas bahwa $G_{i j}$ bukan himpunan kosong karena $e=a^{n} \in G_{i j}$, Selanjutnya ambil sebarang $x, y \in G_{i j}$, tulis $x=a^{r} b^{s}$ dan $y=a^{u} b^{v}$. 
Karena $\quad y^{-1}=b^{-v} a^{n-u}=b^{-v} a^{-u}$ diperoleh $x y^{-1}=a^{r} b^{s} b^{-v} a^{-u}$.

Perhatikan bahwa untuk $s=0$ maka $r=$ $0, p_{i}, 2 p_{i}, \ldots, n-p_{i}$ sedangkan jika $s=1$ maka $r=k, k+p_{i}, k+2 p_{i}, \ldots, k+n-p_{i} \quad$ untuk suatu $k \in \mathbb{N}, 0 \leq k<p_{i}$. Demikian juga untuk $u$ dan $v$.

$\underline{\text { Kasus } 1} \quad s=v=0$ maka $x y^{-1}=a^{r}\left(a^{u}\right)^{-1}=$ $a^{r} a^{n-u}$ dimana $r=l_{1} p_{i} \quad$ dan $u=l_{2} p_{i}$ akibatnya $\quad a^{l_{1} p_{i}} a^{n-l_{2} p_{i}}=a^{n+\left(l_{1} p_{i}-l_{2} p_{i}\right)}=$ $a^{n+\left(l_{1}-l_{2}\right) p_{i}}=a^{\left(l_{1}-l_{2}\right) p_{i}}$. Dengan demikian terbukti $x y^{-1} \in G_{i j}$.

$\underline{\text { Kasus } 2} \quad s=1, v=0$ maka $x y^{-1}=$ $a^{r} b\left(a^{u}\right)^{-1}=a^{r} b a^{n-u}=a^{r} a^{u} b$ dimana $r=$ $k+l_{1} p_{i} \quad$ dan $\quad u=l_{2} p_{i} \quad$ akibatnya $a^{k+l_{1} p_{i}} a^{l_{2} p_{i}} b=a^{k+\left(l_{1} p_{i}+l_{2} p_{i}\right)} b=$

$a^{k+\left(l_{1}+l_{2}\right) p_{i}} b=a^{k+\left(l_{1}+l_{2}\right) p_{i}} b$. Dengan demikian terbukti $x y^{-1} \in G_{i j}$.

$\underline{\text { Kasus } 3} \quad s=0, v=1 \quad$ maka $x y^{-1}=$ $a^{r}\left(a^{u} b\right)^{-1}=a^{r} b^{-1} a^{n-u}=a^{r} a^{u} b \quad$ dimana $r=l_{1} p_{i} \quad$ dan $\quad u=k+l_{2} p_{i} \quad$ akibatnya $a^{l_{1} p_{i}} a^{k+l_{2} p_{i}} b=a^{k+\left(l_{1} p_{i}+l_{2} p_{i}\right)} b=$ $a^{k+\left(l_{1}+l_{2}\right) p_{i}} b=a^{k+\left(l_{1}-l_{2}\right) p_{i}} b$. Dengan demikian terbukti $x y^{-1} \in G_{i j}$.

$\underline{\text { Kasus } 4} \quad s=1, v=1 \quad$ maka $x y^{-1}=$ $a^{r} b\left(a^{u} b\right)^{-1}=a^{r} b b^{-1} a^{n-u}=a^{r} e a^{n-u}=$ $a^{r} a^{n-u}$ dimana $r=k+l_{1} p_{i}$ dan $u=k+l_{2} p_{i}$ akibatnya $a^{k+l_{1} p_{i}} a^{n-k-l_{2} p_{i}}=a^{n+\left(l_{1} p_{i}-l_{2} p_{i}\right)} b=$ $a^{n+\left(l_{1}-l_{2}\right) p_{i}} b=a^{\left(l_{1}-l_{2}\right) p_{i}} b$. Dengan demikian terbukti $x y^{-1} \in G_{i j}$.

Dari empat kasus di atas terbukti bahwa $G_{i j}$ subgrup nontrivial dari $D_{2 n}$.

\section{Daftar Pustaka}

David, S Dummid and Foote, Richard M. 1991. Abstrak Algebra. New Jersey: Division of Simon \& Schauster, Inc.

Fraleigh, John. 1997. A First Course In Abstract Algebra, Seventh Edition. United States of America : Pearson Education Limited.

Herstein, I. N. 1975. Topics in Algebra, Second Edition. Singapura : John Wiley \& Sons. 